\title{
Convenciones, prácticas empresariales y pautas para el desarrollo económico y territorial. Las industrias del vino y del calzado en la provincia de Zaragoza
}

\author{
Ana Isabel Escalona OrCAO \\ Blanca Loscertales PALOMAR \\ Eugenio Climent LóPEZ \\ ecliment@unizar.es
}

Recibido: 29 de Noviembre de 2010

Enviado a evaluar: 3 de Marzo de 2011

Aceptado: 28 de Junio de 2011

\section{RESUMEN}

El artículo se centra en dos áreas rurales aragonesas afectadas por procesos de reestructuración en sectores clave de sus economías: la Denominación de Origen vitivinícola de Calatayud y el valle del río Aranda, especializado en la industria del calzado. Una vez presentada la problemática de ambas áreas, se analizan y comparan las diferentes estrategias empresariales. La teoría de las convenciones y el nuevo paradigma de desarrollo rural constituyen el marco teórico de dicho análisis y aportan los elementos para una encuesta sobre la trayectoria empresarial reciente y sus implicaciones para el desarrollo de ambos territorios. Los resultados muestran, con matices, la decidida apuesta de las empresas por la innovación, la calidad y la internacionalización, así como las demandas de las empresas para la mejora de su situación en el territorio. El artículo concluye con diversas propuestas para diseñar políticas adecuadas a los actuales retos de las áreas rurales.

Palabras clave: Sector vitivinícola, fabricación de calzado, convenciones productivas, desarrollo rural.

Conventions, Business practices and guidelines for economic development and territorial. The wine industry and footwer in the province of Zaragoza

\begin{abstract}
The paper analyses the relationship between the strategies of rural firms and the economic and territorial development. Two rural areas affected by economic restructuring processes are selected for the study: the Calatayud Protected Designation of Origin and the Aranda valley, specialised in footwear industries. The theory of conventions and the new paradigm of rural development provide the theoretical framework of this analysis, which includes the application of a survey aimed to assess the different strategies undertaken by firms and to allow comparisons between the two sectors. The results show, with nuances, the strong commitment of enterprises for innovation, the pursuit of quality and the internationalization of their markets. The demands of companies to improve their situation in the territory appear clearly highlighted as well. The article concludes with several proposals to design appropriate policies to the current challenges facing rural areas.
\end{abstract}

Key words: Wine industry, footwear industry, conventions, rural development

\section{RESUMÉ}

L'article traite de la problématique de deux zones rurales d'Aragon touchées par les restructurations dans les secteurs clés de leurs économies: l'Appellation d'Origine Contrôlée du vin Calatayud et la 
vallée de la rivière Aranda, spécialisée dans la fabrication de chaussures. La théorie des conventions et le nouveau paradigme du développement rural constituent le cadre théorique et fournissent les éléments pour l'élaboration d'une enquête sur les stratégies de production des entreprises et leur perception de l'environnement économique. Les résultats montrent, avec des nuances, l'engagement clair des entreprises des deux secteurs avec l'innovation, la qualité et l'internationalisation des marchées. Les demandes des entreprises pour améliorer leur situation dans le territoire sont aussi clairement exposées. L'article se termine avec la proposition de plusieurs politiques appropriées aux défis actuels auxquels font face les zones rurales.

Mots clef: vin, chaussures, conventions, développement rural

\section{INTRODUCCIÓN}

El artículo se plantea como principal objetivo llevar a cabo un análisis comparado de la situación de dos áreas especializadas en la producción de vino y calzado e inmersas en un proceso de profunda reestructuración; se evalúan las principales estrategias llevadas a cabo por las diferentes empresas y se establecen diversas pautas orientadas a mejorar el desarrollo y la competitividad actual y futura de estos territorios. ${ }^{1}$

El espacio estudiado se localiza en el suroeste de la provincia de Zaragoza y abarca el territorio de la Denominación de Origen Calatayud, la más reciente de las tres Denominaciones de Origen vitivinícolas de la provincia de Zaragoza, y el valle del río Aranda, dedicado tradicionalmente a la fabricación de calzado. Este espacio ha perdido durante el siglo pasado una parte importante de su población y tiene planteados graves problemas demográficos, especialmente por su envejecimiento. Por otra parte, existen marcadas diferencias en la localización espacial de la población y de sus asentamientos. El reducido tamaño de los mismos y la baja densidad de población de sus municipios es una característica esencial. La llegada reciente de inmigrantes en los últimos años puede ser un indicador del inicio de una nueva trayectoria demográfica, pero, lógicamente, es desigual. Los diferentes actores locales han apostado por seguir un modelo de desarrollo endógeno, a partir de sus propios recursos naturales, del saber hacer tradicional y de la innovación necesaria para responder a la situación actual. Estos aspectos son esenciales para la pervivencia y competitividad de ambos sectores de cara a un desarrollo territorial sostenible.

La mundialización económica ha producido nuevos retos a los que las empresas deben dar una respuesta adecuada. Para conocer, analizar y evaluar las estrategias productivas llevadas a cabo por las mismas con el objetivo de reforzar la competitividad,

${ }^{1}$ En el artículo se recogen de modo sintético los resultados de dos proyectos: 1) Nuevos retos para el desarrollo territorial. Los espacios del vino y del calzado en la provincia de Zaragoza. El proyecto resultó seleccionado en la I Convocatoria de los Premios de Investigación Zaragoza Provincia. Cuarto Espacio, de la Diputación Provincial de Zaragoza. Los autores agradecen a esta Institución su patrocinio del trabajo. 2) Gobernanza, innovación y convenciones en las comarcas vitivinícolas de Aragón: tipología y prospectiva de Denominaciones de Origen a partir de la teoría de los "mundos de producción". Se trata de un proyecto coordinado subvencionado por la DGCYT, cuyas entidades participantes son la Universidades de Salamanca, Zaragoza y Complutense de Madrid. Su objetivo es el análisis de 17 Denominaciones de Origen partir de las teorías de las Convenciones y de los Mundos de Producción. 
se realizaron paralelamente dos encuestas semejantes y durante el mismo período de tiempo. Algunos de los principios que sustentan las diferentes prácticas productivas se analizan a partir de la teoría de las convenciones al considerar que ésta proporciona un marco útil. La encuesta deja claras las numerosas coincidencias existentes entre las estrategias llevadas a cabo por las empresas dedicadas a la producción vinícola y las del calzado: ello indica que las prácticas empresariales de ambas se plantean objetivos similares.

El artículo concluye recogiendo diferentes propuestas a los actores económicos, encaminadas a que puedan afrontar con éxito los nuevos desafíos y conseguir el desarrollo sostenible de sus áreas rurales.

\section{LA ZONA DE ESTUDIO. PRESENTACIÓN E IMPORTANCIA DE LAS ACTIVIDADES VITIVINÍCOLAS Y DE FABRICACIÓN DE CALZADO}

El área estudiada está situada al suroeste de la provincia de Zaragoza. En el caso del territorio del Valle del Aranda, el criterio de selección de los nueve municipios que lo integran ha sido la vinculación con el sector productivo del calzado. En algunos de ellos hay fábricas de calzado o industrias auxiliares, mientras que en los otros se dan movimientos pendulares laborales de su población activa para trabajar en las fábricas de los primeros citados. El territorio de la DO Calatayud está formado por 46 municipios. La superficie total del área de estudio es de $2.226,9 \mathrm{~km}^{2}$, que representa un $12,9 \%$ de la de la provincia de Zaragoza. El número de habitantes en el año 2008 ascendía a 38.885 en la DO Calatayud y a 8.543 en lo que hemos denominado territorio del calzado; la figura 1 recoge su distribución espacial. La densidad de población media para el conjunto de esta área era en dicho año de 21,9 habitantes por $\mathrm{km}^{2}$. Si se excluye la mayor población del municipio de Calatayud (21.905 habitantes), la densidad es de tan sólo 11,5 habitantes por $\mathrm{km}^{2}$, cifra muy próxima a lo que se considera un desierto demográfico.

Figura 1. Distribución municipal de la población

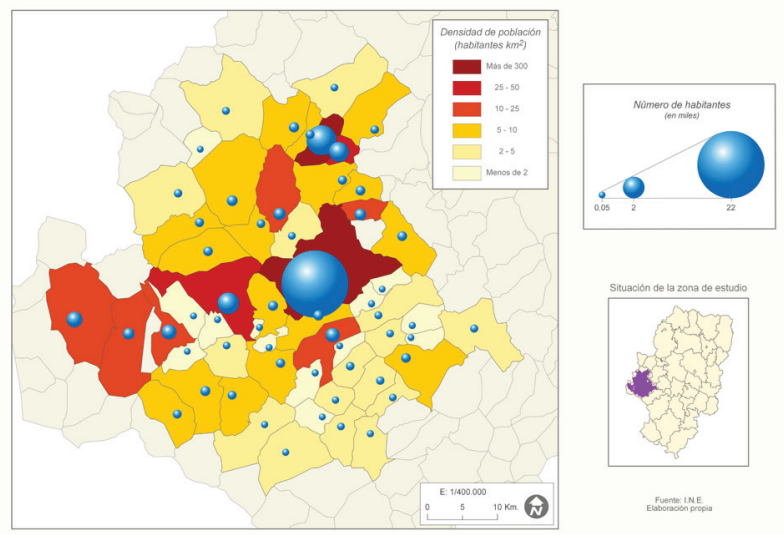

Fuente: Adaptado de Escalona et al. (2009). 
Como se puede ver en el mapa, el área se parcela en un gran número de municipios, generalmente muy poco poblados. La intensa emigración rural que en su última fase tuvo lugar en el inicio de la segunda mitad del siglo XX, explica el exiguo tamaño demográfico de muchos de los mismos y el intenso envejecimiento de su población: la de más de 65 años arroja un valor porcentual en torno al 35\%. Ello es muy preocupante ya que pone en riesgo el relevo generacional y, por tanto, el futuro de las actividades económicas en el territorio.

En el territorio de la DO Calatayud se contabilizan 5.621 hectáreas de viñedo, localizadas especialmente en zonas altas, sobre terrenos con elevada pendiente, lo que favorece la aireación, pero dificulta la mecanización, por lo que la mayoría de las labores de cultivo se realizan de forma manual. Las características de sus vinos son el resultado de la interacción de diferentes factores medioambientales como el relieve, los suelos y las características climáticas. La principal variedad de uva es la garnacha, autóctona y perfectamente adaptada a la zona, con plantaciones que superan en muchos casos los 50 años de edad y de la que se obtienen vinos con una marcada personalidad. La vitivinicultura ha venido siendo en esta área una actividad tradicional y una base económica importante. Todavía en muchos de los pequeños municipios tiene un elevado peso en el conjunto de la agricultura y de la industria local (figura 2), especialmente desde la aparición en 1989 de la DO (Escalona et al., 2010).

Figura 2: Distribución espacial y tamaño de las empresas del vino en la DO Calatayud

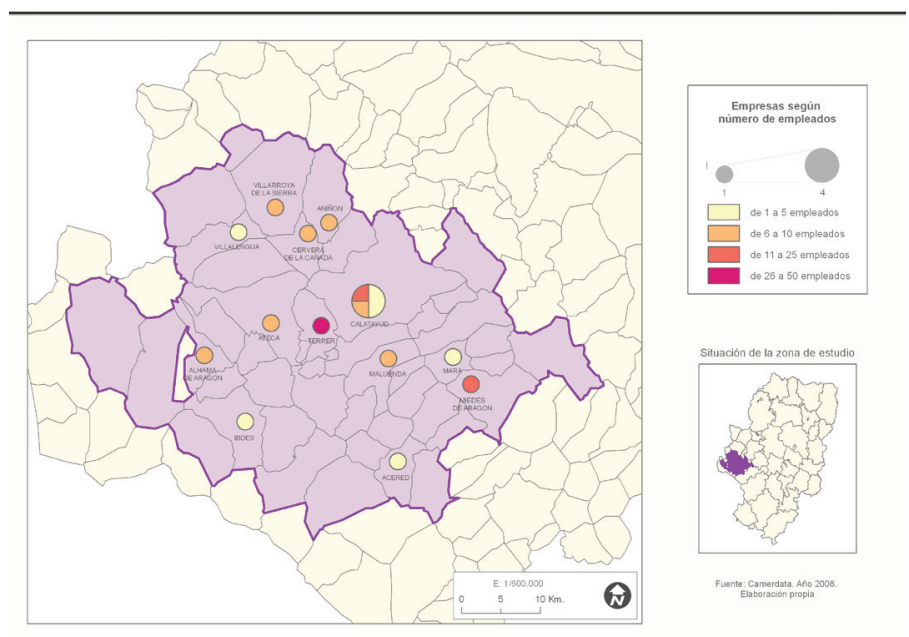

Fuente: Adaptado de Escalona et al., 2009.

La comarca zaragozana del Aranda es la principal área productora de calzado de Aragón y la cuarta a escala nacional por el volumen de producción en el año 2008; sin embargo, está lejos de otras áreas españolas, como la Comunidad Valenciana (Escalona et al., 2009). El carácter endógeno de sus empresas, la importancia de la empresa familiar, dirigida por los herederos de quienes iniciaron el negocio, o la 
incorporación como empresarios de antiguos trabajadores, son rasgos distintivos que favorecen la conservación de los valores patrimoniales heredados, fruto del saber hacer y de la tradición. Algunas de sus técnicas, como la del punteado, tienen un amplio reconocimiento internacional. La industria del calzado representa el $63 \%$ del empleo industrial local, indicando su fuerte implantación en el territorio, y supone cerca del 98\% del total de contratos del sector secundario (Montealegre, 2009). La figura 3 muestra la notable concentración espacial de la actividad, que se ve compensada por la existencia de intensos movimientos intermunicipales de trabajadores.

Figura 3: Distribución de las empresas y el empleo en el sector del calzado en el Valle del Aranda

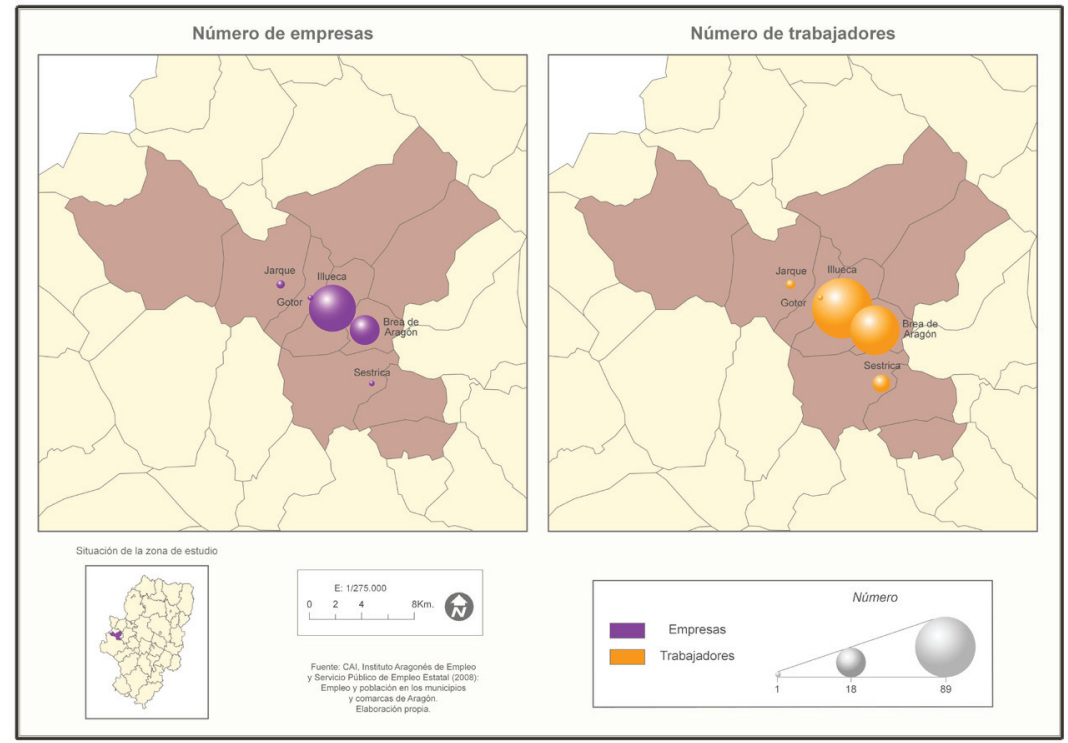

Fuente: Adaptado de Escalona et al., 2009.

Ambos sectores productivos están inmersos a escala mundial en un proceso de reestructuración asociado a la situación del mercado mundial y al notable aumento de la competencia a todas las escalas, lo cual se refleja en la trayectoria socioeconómica actual del territorio estudiado. Una clara amenaza para el sector del calzado es la deslocalización productiva ya que puede incidir negativamente en la evolución del empleo y en la de la producción (figura 4).

Por otra parte, las presiones del mercado mundial pueden llevar a ajustar el potencial productivo actual en los espacios vitivinícolas. En la DO Calatayud la cosecha de 13 millones de kilos de uva, recogidos en la vendimia de 2009, representa un 35\% menos que la media histórica de la denominación, con 20 millones de kilos (figura 5). La reducción de la superficie cultivada relacionada con el arranque de viñedos es quizá su principal causa. Esta y otras circunstancias influyen en la producción de vino embotellado, que tiende a estabilizarse en torno a los 5,5 millones de botellas (figura 6). 
Figura 4: Evolución de la producción de calzado en Aragón

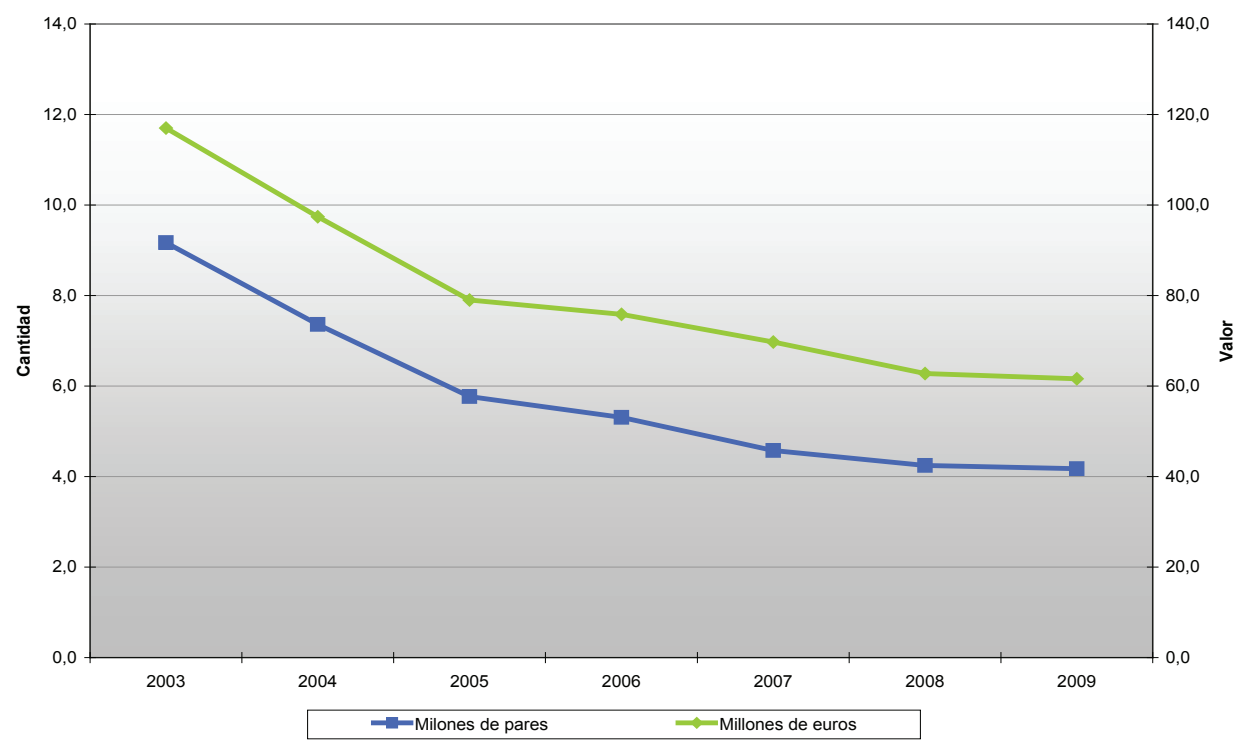

Fuente: Fuente: Federación de Industrias del Calzado Español (http://www.fice.es)

Figura 5: Cosechas de uva en el territorio de la DO Calatayud

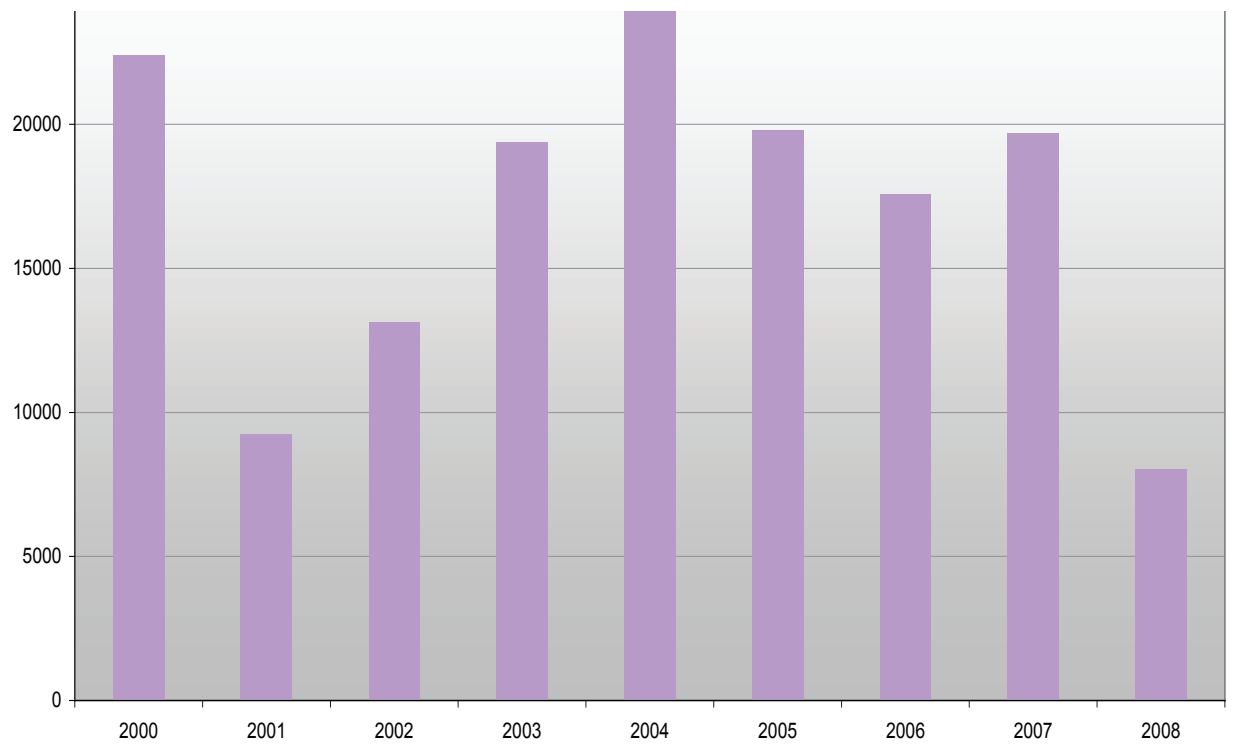

Fuente: Consejo Regulador de la DO Calatayud 
Figura 6: Evolución de la producción de vino embotellado en la DO Calatayud:

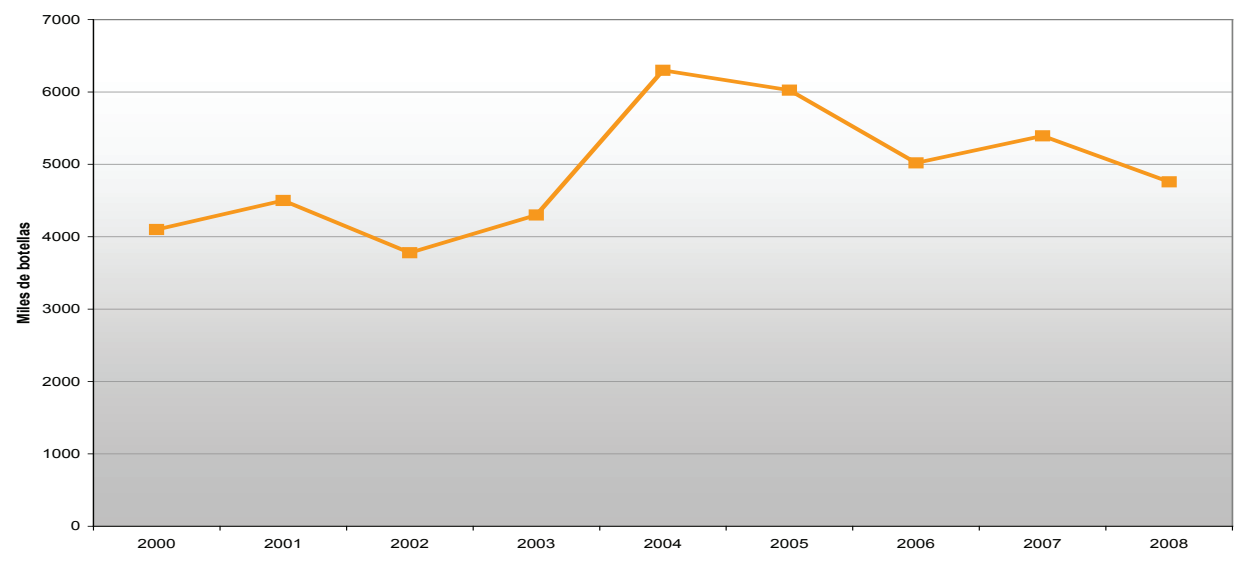

Fuente: Consejo Regulador DO Calatayud

\section{RETOS Y EXPECTATIVAS DE MERCADO EN LOS SECTORES DEL CALZADO Y DEL VINO}

\subsection{LOS PROCESOS DE GLOBALIZACIÓN E INTEGRACIÓN DE LOS MERCADOS}

La evolución reciente de las producciones vinícolas y de calzado en esta área se relaciona directamente con el creciente proceso de integración del comercio mundial, que ha impactado al territorio y ha dado lugar a un notable incremento de la competencia de otros ámbitos productivos. A ello hay que sumar, la creciente tendencia a la liberalización de los intercambios internacionales y el dinamismo económico de los nuevos países productores. En el caso del calzado, el menor coste de la mano de obra en algunos países en desarrollo es un importante factor para el incremento del sector. En el caso del vino, los nuevos países productores están situados en diferentes áreas geográficas del mundo con condiciones bioclimáticas similares a las de Europa mediterránea (Australia y Nueva Zelanda, Norteamérica y Sudamérica, Sudáfrica). Cabe destacar en todos ellos una legislación menos rígida y su capacidad para competir con los países productores y exportadores tradicionales en los segmento de precios medios y medios altos, como consecuencia de que han realizado una gran inversión en tecnología. Sin embargo, en el sector del calzado la tecnología supone cada vez más un elemento de diferenciación (Escalona et al., 2009; Barco, 2007; Barco et al., 2006; Albisu, 2005).

Este complejo contexto explica los debates suscitados a escala internacional en la regulación de los mercados del vino y del calzado. En el caso del calzado, resulta controvertida la posible prórroga de los aranceles antidumping establecidos por la Unión Europea en 2006 para el calzado de piel importado desde China y Vietnam, buscando penalizar la venta por debajo del coste y las prácticas de competencia desleal. 
La Confederación Europea de Fabricantes de Calzado, respaldada por el 35\% de los productores europeos de calzado de piel, entre los que destacan los italianos y los españoles, se muestra partidaria de la prórroga, por entender que no han desaparecido las prácticas ilícitas que determinaron en su día la aplicación de tales medidas. Distinta es la postura de los empresarios con fábricas en tales países y de los distribuidores, al considerar que esta medida no sólo es contraria a sus intereses y a los de los consumidores sino que tampoco está evitando el declive de esta industria (FICE, 2008).

En el caso de la producción vinícola, el debate se ha planteado en torno a la aprobación de la nueva Organización Común del Mercado del sector vitivinícola ${ }^{2}$, justificada por los diversos problemas que afectaban al sector, como la disminución del consumo, el aumento de los excedentes o el deterioro de la renta de los productores agrarios. Las disposiciones adoptadas por la Unión Europea en 2008 han sido criticadas, entre otros motivos, por asumir que existe un único modelo europeo de producción y por primar un enfoque centrado en un aspecto tan polémico como es el arranque de viñedos, olvidando otros aspectos importantes, como tomar determinadas medidas para favorecer el consumo. La mejora de la calidad, de la comunicación en el mercado interior de la Unión Europea, las ayudas económicas o inversiones para actuar en el exterior, son otras actuaciones alternativas a las adoptadas por las autoridades europeas (Barco, 2007).

La actual crisis económica ha generado un impacto muy negativo en estos sectores, ya que en ambos productos la demanda es elástica y ello facilita, por ejemplo, la disminución del consumo del vino. En ambos sectores, la exportación constituye una salida imprescindible para la producción española. Por ello, en el caso del vino, las diferentes DO zaragozanas, y la de Calatayud no es una excepción, están llevando a cabo diversas actuaciones comerciales encaminadas a favorecer el incremento de sus exportaciones (Escalona et al., 2009; Loscertales, 2009)

\subsection{EXPECTATIVAS DE LOS MERCADOS. LA VALORACIÓN DEL VINO Y DEL CALZADO POR PARTE DE LOS CONSUMIDORES}

La profunda reestructuración del mercado mundial obliga a las empresas de calzado del valle del Aranda y a las bodegas de la DO Calatayud, como a las de otras áreas productivas, a tratar de mantener el mercado en el que han venido estando presentes y aprovechar también las nuevas oportunidades, fruto de la globalización económica, buscando nuevos mercados y los nichos más adecuados. Al parecer, los productos de mayor calidad, los más diferenciados, atraen a los consumidores más exigentes, que no dudan en pagar por ellos precios más elevados; eso les garantiza unas mayores posibilidades de futuro (Escalona et al., 2009).

Por ejemplo, en el caso del vino, una adecuada política de marketing, que dé a conocer aspectos como la calidad del producto, su origen o el conjunto de su proceso productivo, ayuda a que los consumidores elijan aquellos vinos cuyas etiquetas les informan del qué, dónde, cómo y quién del proceso de producción (Lindkvist y Sánchez, 2008: 351). En esta línea, la pertenencia a una DO aparece como garantía de la calidad de una producción y facilita su identificación con un territorio concreto y con las prácticas culturales que le son propias (Barco et al., 2006).

\footnotetext{
${ }^{2}$ Reglamento (CE) No 479/2008 del Consejo, de 29 de abril.
} 
Respecto al calzado, desde la Unión Europea, con el fin de apoyar la fabricación propia como un valor añadido de las empresas que la mantienen, se está pensando en imponer una etiqueta de origen para todo el calzado importado. No obstante, no hay unanimidad entre los empresarios sobre esta novedosa iniciativa, ni respecto de su oportunidad o conveniencia, como veremos más adelante. En la base de las diferentes campañas orientadas a prestigiar el calzado fabricado en España, se resaltan el diseño y la innovación (FICE, 2008).

En la tabla 1 se recogen diferentes aspectos que explican que productos con costes de elaboración y calidad semejantes puedan alcanzar precios muy diferentes en el mercado (Albisu, 2005). Dicha tabla indica que los consumidores aprecian cualidades semejantes tanto en el vino como en el calzado, por la influencia de la moda y la reducción en el ciclo de vida de los diversos productos. Las empresas, con independencia del sector productivo, deben adaptarse a las nuevas demandas con rapidez. En este marco, el artículo plantea posibilidades muy interesantes de transferencia de estrategias entre los dos sectores considerados, aspecto que se recoge a continuación.

\section{ESTRATEGIAS EMPRESARIALES Y DESARROLLO TERRITORIAL EN LA DO CALATAYUD Y EL VALLE DEL ARANDA}

\subsection{FUNDAMENTOS DEL ANÁLISIS: SÍNTESIS DE LAS CONVENCIONES PRODUCTIVAS Y CORPORATIVAS DE LAS EMPRESAS VINÍCOLAS Y DE FABRICACIÓN DE CALZADO.}

En el mercado mundial existen complejos y diversos retos a los que se enfrentan las empresas de las áreas productoras del vino y del calzado. Para dar una respuesta adecuada, las empresas ajustan sus estrategias productivas y corporativas según su percepción del contexto socioeconómico y sus expectativas en relación con la calidad y el precio de los productos (Sánchez et al., 2010; Ponte, 2009).

Tabla 1. Ejemplos de aspectos valorados por los consumidores para adquirir vinos y calzados de calidad

\begin{tabular}{|c|c|c|}
\hline Aspecto & Vinos & Calzado y sus componentes \\
\hline $\begin{array}{l}\text { Presentación del } \\
\text { producto }\end{array}$ & $\begin{array}{l}\text { - Tipo de botella } \\
\text { - Etiquetado, botella, corcho }\end{array}$ & $\begin{array}{l}\text { - Diseño } \\
\text { - Incorporación de elementos } \\
\text { de moda }\end{array}$ \\
\hline $\begin{array}{l}\text { Información } \\
\text { aportada sobre el } \\
\text { producto }\end{array}$ & $\begin{array}{l}\text { - Características } \\
\text { - Certificación de su origen } \\
\text { y calidad y de haber sido } \\
\text { elaborado de modo sostenible }\end{array}$ & $\begin{array}{l}\text { - Nuevas prestaciones y } \\
\text { especialización según uso } \\
\text { - Garantía del cumplimiento } \\
\text { de los diferentes controles } \\
\text { y requisitos de calidad y } \\
\text { sostenibilidad } \\
\text { Que sea beneficioso para la } \\
\text { salud }\end{array}$ \\
\hline $\begin{array}{l}\text { Imagen del producto } \\
\text { seguin ... }\end{array}$ & $\begin{array}{l}\text { - Valoración por los } \\
\text { consumidores } \\
\text { - Crítica positiva en medios } \\
\text { especializados y premios } \\
\text { obtenidos }\end{array}$ & $\begin{array}{l}\text { - Valoración de la marca. } \\
\text { - Crítica positiva en medios } \\
\text { especializados y premios } \\
\text { obtenidos }\end{array}$ \\
\hline
\end{tabular}

Fuente: adaptado a partir de Escalona et al. (2009 y 2010), Albisu (2005) y FICE (2008). 
La teoría de las convenciones, desarrollada a partir del concepto acuñado en su día por Salais y Storper (1992), asume que diversas prácticas empresariales pueden derivar de normas o principios admitidos tácitamente. En la tabla 2 presentamos algunos ejemplos, clasificados según los ámbitos de referencia que establece la propia teoría.

Tabla 2: Ejemplos de prácticas empresariales en los sectores del vino y el calzado según la teoría de las convenciones.

\begin{tabular}{|c|c|c|}
\hline $\begin{array}{l}\text { ÁMBITO DE } \\
\text { REFERENCIA }\end{array}$ & $\begin{array}{l}\text { EJEMPLOS DE POSIBLES PRÁCTICAS } \\
\text { EMPRESARIALES }\end{array}$ & $\begin{array}{l}\text { EXPECTATIVAS QUE } \\
\text { LAS JUSTIFICAN }\end{array}$ \\
\hline COMERCIAL & $\begin{array}{l}\text { - Buscar mercados atractivos } \\
\text { - Orientarse hacia determinados nichos de } \\
\text { mercado } \\
\text { - Seleccionar los canales de venta }\end{array}$ & $\begin{array}{l}\text { Características propias } \\
\text { del mercado }\end{array}$ \\
\hline INDUSTRIAL & $\begin{array}{l}\text { - Elección de la materia prima adecuada } \\
\text { - Utilización de tecnologías productivas } \\
\text { - Aspecíficas } \\
\text { - poustar el volumen de la producción a la } \\
\text { - Diversificar los productos } \\
\text { - Reducir la gama de productos }\end{array}$ & $\begin{array}{l}\text { Preferencias del } \\
\text { consumidor por } \\
\text { determinados productos y } \\
\text { procesos de producción }\end{array}$ \\
\hline $\begin{array}{l}\text { DOMÉSTICO O } \\
\text { PROPIO DEL } \\
\text { ENTORNO }\end{array}$ & $\begin{array}{l}\text { - Utilizar preferentemente materias primas de } \\
\text { la zona y hacerlo explícito } \\
\text { - Mantener una producción tradicional } \\
\text { - Identificar el origen y las diferentes } \\
\text { etapas del proceso de producción y del de } \\
\text { distribución. } \\
\text { - Vender en la propia empresa o en tiendas } \\
\text { - especializadas de su entorno. } \\
\text { - Incorporar elementos para la promoción del } \\
\text { territorio en los productos e instalaciones } \\
\text { - Favorecer la conservación del paisaje } \\
\text { tradicional } \\
\text { - Mejorar y difundir el atractivo turístico del } \\
\text { territorio mediante la creación de rutas, } \\
\text { museos temáticos. }\end{array}$ & $\begin{array}{l}\text { Aprecio del } \\
\text { consumidor por los } \\
\text { valores tradicionales } \\
\text { y patrimoniales del } \\
\text { territorio }\end{array}$ \\
\hline ECOLÓGICO & $\begin{array}{l}\text { - Velar por la sostenibilidad del proceso } \\
\text { productivo } \\
\text { - Obtener las acreditaciones oficiales } \\
\text { oportunas } \\
\text { - Establecer líneas de productos ecológicos }\end{array}$ & $\begin{array}{l}\text { Valoración por el } \\
\text { consumidor de los } \\
\text { productos obtenidos de } \\
\text { forma sostenible }\end{array}$ \\
\hline$P U ́ B L I C O$ & $\begin{array}{l}\text { - Estar presentes en diferentes medios } \\
\text { especializados o no } \\
\text { - Participar en certámenes de prestigio con } \\
\text { productos triunfadores }\end{array}$ & $\begin{array}{l}\text { El reconocimiento o la } \\
\text { difusión de la marca } \\
\text { propia }\end{array}$ \\
\hline CÍVICO & $\begin{array}{l}\text { - Elaborar productos saludables } \\
\text { - Participar en campañas de apoyo a causas } \\
\text { humanitarias }\end{array}$ & $\begin{array}{l}\text { La valoración de la } \\
\text { contribución de las } \\
\text { empresas al bienestar } \\
\text { social }\end{array}$ \\
\hline
\end{tabular}

Fuente: Adaptado de Escalona et al., 2010. 


\subsection{LA ENCUESTA A LAS EMPRESAS DEL VINO Y DEL CALZADO}

La investigación realizada para verificar la aplicación por las empresas de alguna de las prácticas recogidas en la tabla 2 se llevó a cabo mediante la realización de una encuesta, estructurada en tres bloques de preguntas, a diferentes empresarios de ambos espacios $^{3}$.

El primer bloque de cuestiones se orientó a la caracterización de la empresa a partir del análisis de la estructura empresarial y de sus posibles variantes. El segundo buscaba conocer la trayectoria empresarial reciente de cada una de las entidades encuestadas; por ello incluía preguntas sobre los productos y los cambios introducidos, la organización productiva y su evolución, los canales de venta utilizados y el peso de cada uno de ellos. Pretendía también conocer los diferentes segmentos de la producción según su calidad, el precio de cada uno de los mismos y sus variaciones según el lugar de venta. Las respuestas de todos ellos permiten conocer muchas de las prácticas admitidas tácitamente por las empresas en lo comercial, industrial, ecológico público y cívico.

El tercer bloque tenía como objetivo conocer la situación real del sector del vino en la DO Calatayud y del sector del calzado en el valle del Aranda y la percepción de los empresarios sobre diferentes cuestiones como la valoración de la situación de sus empresas en relación a las de otros lugares, la permanencia del sector como actividad económica clave para la zona, el apoyo prestado por la Administración o las estrategias necesarias en el marco de un mercado y de una economía global. Las respuestas de los encuestados reflejan su aprecio por el territorio y su opinión sobre diversas prácticas relacionadas con las convenciones domésticas (tabla 2). La muestra a la que hacen referencia los datos y en la que hemos basado nuestras conclusiones está integrada por seis empresas fabricantes de calzado y una de componentes (plantillas) y diez empresas vitivinícolas (Escalona et al., 2010).

\subsection{PRINCIPALES CARACTERÍSTICAS DE LAS EMPRESAS INCLUIDAS EN LA MUESTRA}

Según los datos recogidos en la encuesta cabe afirmar la débil concentración empresarial, lo que era de esperar al tratarse de un modelo productivo tradicional. En el sector del calzado destacan pequeñas empresas de tipo familiar dirigidas por la segunda o la tercera generación, lo que indica su arraigo en el territorio; cuenta con un mayor número de trabajadores fijos y con una mayor proporción de trabajadores eventuales que el sector del vino; tanto éstos como los permanentes, proceden también de los municipios vecinos. El rango en el volumen de producción también es alto, de modo que la de mayor producción multiplica por 4,5 el número de pares producido por la más pequeña y por 3,5 el volumen de producción medio de la zona, que es de 52.430 pares (FICE, 2008).

En el caso del vino el perfil medio de la empresa queda marcado especialmente por la presencia de cinco empresas cooperativas, que son las más antiguas y superan

${ }^{3}$ Agradecemos a D. Jesús Miñana, empresario del valle del Aranda, su inestimable ayuda en la selección de las empresas de calzado de la muestra y en la distribución y realización de las encuestas. 
ampliamente la producción media de la DO por bodega, que era en 2008 de 0,32 millones de litros. Junto a ellas se identifican también algunas empresas de carácter familiar. Las empresas vinícolas se ubican con una mayor dispersión en el territorio que las del calzado.

\subsection{LA TRAYECTORIA EMPRESARIAL RECIENTE: PRINCIPIOS Y PRÁCTICAS}

\subsubsection{La mejora de la calidad y la búsqueda de una producción diferenciada}

Las diversas innovaciones llevadas a cabo por las empresas tienen como objetivo la búsqueda de nuevos productos y su diversificación. Así lo afirman seis de las siete empresas de calzado encuestadas y diez de las once bodegas. Es un reto la elaboración de productos singulares y de calidad orientados a dar respuesta a las exigencias de los consumidores. Como tal está, sin duda, en la base de las modificaciones realizadas en la gama habitual de productos o en la puesta en el mercado de otros nuevos, en el caso del calzado, o de nuevas variedades de vinos (figura 7).

Las bodegas, especialmente las de carácter familiar, que cuentan en ocasiones con la explotación agraria alrededor, a modo de las francesas de tipo chateau, buscan la mejora de las gamas propias, que incluyen diferentes tipos de vinos, entre los que destacan los elaborados a partir de variedades locales, como la garnacha, especialmente la tinta. Las bodegas experimentan con otras variedades o realizan coupages o mezclas entre distintos vinos como otra forma de innovación. Muchos de los cambios tienen como objetivo adaptar los vinos a los gustos de los consumidores o responder directamente a las exigencias de los importadores y, para ello, cuentan con el asesoramiento, en ocasiones, de expertos enólogos procedentes o formados en los nuevos países productores. Ante la importancia del respeto al medioambiente, cabe destacar la existencia de una bodega inscrita en el Comité de Agricultura Ecológica y de un total de 44,58 has con viñedo ecológico; se utilizan variedades autóctonas, destacando la garnacha; esta práctica muestra cómo las convenciones ecológicas comienzan a estar presentes (tabla 2).

Figura 7. Proporción de empresas encuestadas según la modificación introducida en su oferta productiva.

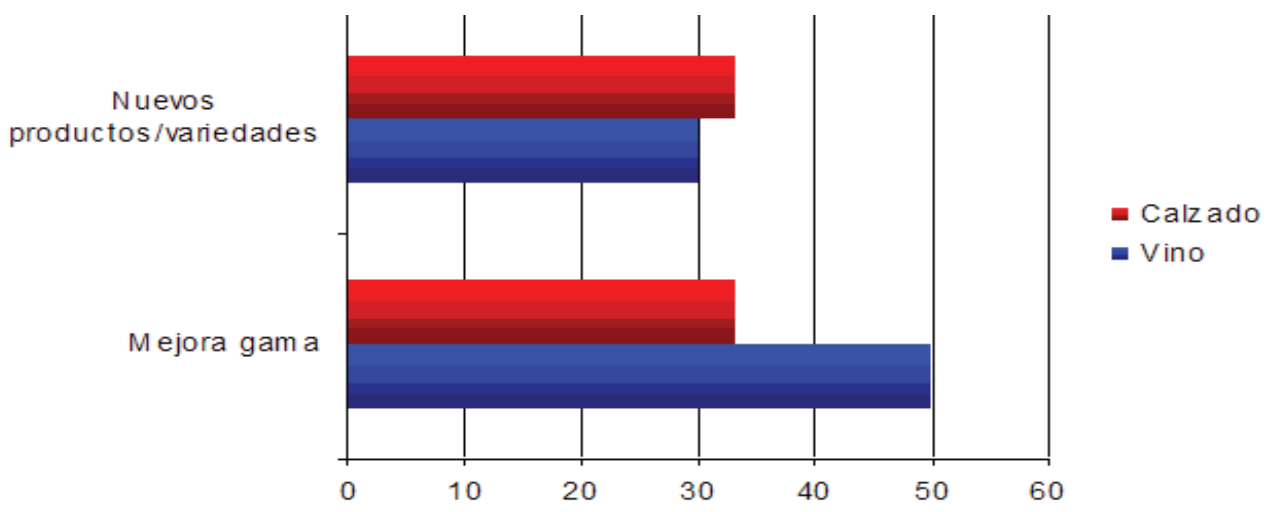

Fuente: Encuesta a las empresarios del vino y del calzado 
Las empresas de calzado encuestadas centran sus mejoras en productos enfocados a más de un segmento de mercado (calzado de niño, joven, señora o caballero) en el $60 \%$ de los casos, pero otras veces la producción se especializa, como en el caso de una empresa que fabrica en exclusiva calzado para mujeres jóvenes o de otra que produce únicamente calzado de caballero. El número de diseños o de modelos fabricados se multiplica. A modo de ejemplo, una de las empresas encuestadas presentó en la edición 2010 de la más importante feria nacional, Modacalzado, entre 150 y 200 nuevos diseños. La encuesta deja patente además la decidida apuesta de las empresas de este sector por competir comercialmente con productos de calidad media y alta (figura 8). Destaca especialmente que ninguna empresa de calzado manifieste que su producción pueda considerarse como de gama media-baja. Ello favorece la tesis de que los vinos y el calzado españoles de mayor calidad y por lo tanto de precio más elevado se adaptan mejor a los nichos de mercado y son más competitivos.

Figura 8: Proporción de empresas encuestadas según segmento de calidad al que pertenece su producción.

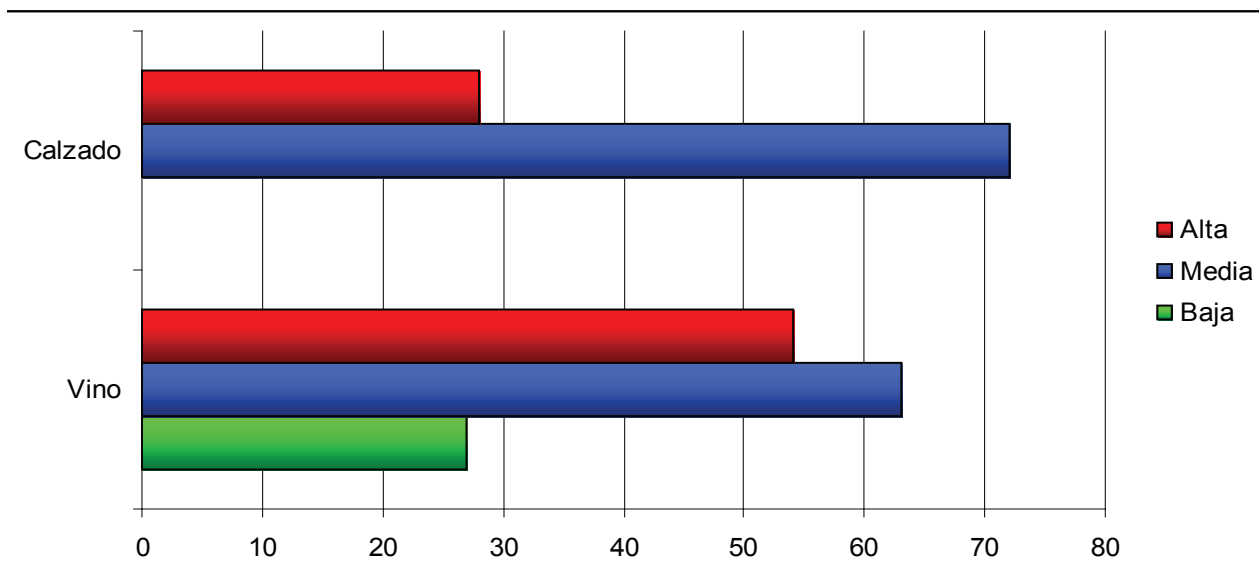

Fuente: Encuesta a los empresarios del vino y del calzado

La encuesta refleja también que, en el caso del calzado, se produce un desajuste entre el precio y la calidad de los mismos, ya que un tercio de las empresas encuestadas afirma que venden calzado por 30 euros o menos el par, un precio inferior al de las gamas en las que fabrican. Sólo una empresa vende sus productos por encima de los 60 euros (umbral establecido en la encuesta para la categoría de valor más alta). Los productos de las restantes se venden en el mercado a un precio que oscila entre los 30 y los 60 euros el par.

\subsubsection{Modificaciones e innovaciones en los aspectos productivos y no productivos}

Ante las dificultades existentes, el 71 ' $4 \%$ de las empresas de calzado y el $72 \%$ de las bodegas han modificado recientemente sus estructuras productivas para responder mejor a las diferentes demandas actuales. En el caso del calzado, las diversas 
respuestas ponen de relieve el afán de los empresarios por mejorar su maquinaria para estar al día (importancia de las convenciones industriales); así lo expone una de ellas con respecto al cortado de las piezas. Otros han optado por subcontratar a otras empresas del entorno. Esta última estrategia, generalizada en los espacios dedicados a la producción de calzado, sirve para reforzar la especialización productiva local y favorece el desarrollo territorial. Cada vez más, no obstante, la subcontratación local se sustituye por la subcontratación en terceros países, si bien ninguna de las empresas encuestadas afirma su práctica, aunque existen diversos casos en ese territorio, como ya ha sido estudiado en otro lugar (Escalona et al., 2009; Montealegre, 2009). Las bodegas, por su parte, amplían o renuevan sus instalaciones e introducen innovaciones diversas.

La encuesta muestra el interés de las empresas de ambos sectores por innovar en otros aspectos muy variados y apreciados por los consumidores como la marca, el diseño y la imagen de los productos (tabla 1); todos ellos son esenciales para reforzar la competitividad (figura 9). Ello muestra el interés por la búsqueda del reconocimiento para la marca propia y, con ello, la importancia de las convenciones públicas.

Según las respuestas obtenidas, las políticas de marketing son objeto de atención y así lo especifican preferentemente las empresas del calzado, quizá porque muchas de ellas carecen todavía de marca propia, lo que reduce su capacidad para crear valor y obtener en el mercado precios acordes con la calidad de sus productos. Tanto las del vino como las del calzado han innovado también en el diseño y la presentación de sus productos. Las del calzado se han centrado en incorporar a los productos las cualidades demandadas por los consumidores (estilo, elementos de moda, confort, flexibilidad). Las bodegas de esta DO se esmeran cada vez más por la presentación externa de sus vinos (tipo de botella, tapón y etiquetado, entre otros aspectos). Las bodegas se esfuerzan por facilitar y dar a conocer el proceso productivo del vino desde el inicio ${ }^{4}$. En ocasiones, las innovaciones pueden ser el fruto de la investigación realizada de forma directa por la empresa o mediante la participación en proyectos auspiciados por instituciones públicas, como ocurre en el mundo del calzado. Es una característica de los modelos empresariales de éxito y, aunque minoritaria, refleja el dinamismo empresarial, ya que supone una clara apuesta para fortalecer su actividad y darle un futuro en el propio territorio ${ }^{5}$.

Las demás opciones de innovación enumeradas en la encuesta, sólo las han introducido una o dos empresas o, en ocasiones, ninguna. Una empresa de calzado ha mejorado el ámbito de la gestión y la administración y es además la que ha introducido mayor número de innovaciones, incluidas las que versan sobre marketing

${ }^{4}$ Es frecuente encontrar en las páginas webs corporativas aplicaciones interactivas que facilitan que el consumidor conozca con detalle la trayectoria o proceso de elaboración de cualquiera de los productos de su bodega.

${ }^{5}$ Destaca la puesta en marcha de dos interesantes proyectos de investigación impulsados por el clúster aragonés del calzado en los que participan empresas encuestadas: Uno se enfoca a desarrollar una nueva línea de calzado infantil, que favorezca el correcto crecimiento del pie del niño y la adopción de una manera adecuada de andar. El otro busca una nueva línea de calzado que permita un aumento sustancial de la comodidad y el confort durante su uso, disminuyendo la fatiga muscular que se genera al caminar. Ambos muestran el interés por la elaboración de productos saludables y, con ello, la importancia de las convenciones cívicas. 
y publicidad. Se trata de una empresa muy puntera, con amplia presencia en mercados internacionales; también la empresa fabricante de plantillas cuenta con innovaciones en cuatro de los apartados de la encuesta, mientras que las dos empresas restantes, han innovado en menos aspectos.

Figura 9: Innovaciones introducidas por las empresas (\% de empresas según sector y tipo de innovación).

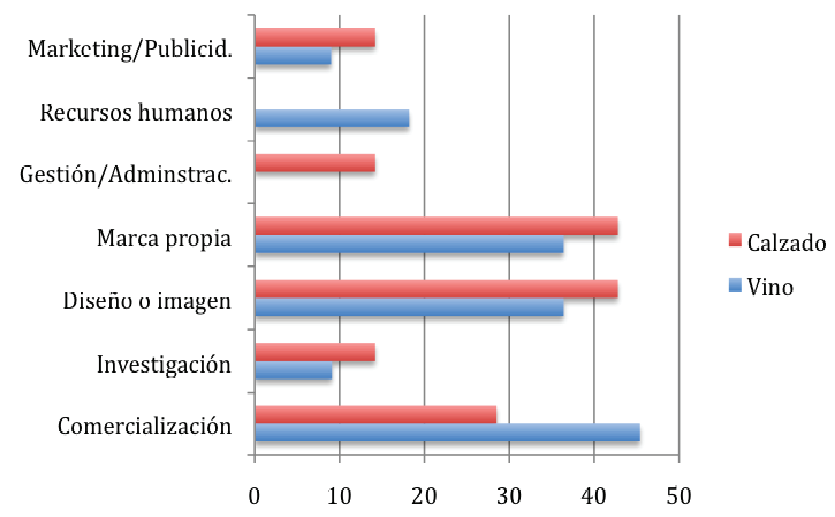

Fuente: Encuesta a las empresarios del vino y del calzado

\subsubsection{Los precios de los productos y sus canales de venta}

Como se ha visto en la tabla 2, las empresas intentan aumentar su presencia en los mercados que consideran más atractivos. Sin embargo, el esfuerzo innovador desarrollado por algunas de las mismas en relación con la comercialización de sus productos no ha supuesto cambios importantes en los canales de venta habituales, incluso teniendo en cuenta que los precios de los vinos y los de los calzados varían según el canal de venta utilizado. Las respuestas a la encuesta sólo dan cuenta de la introducción, como complemento, de nuevas vías de comercialización, como son la venta por Internet, implantada por una de las empresas de calzado más punteras de la muestra; la venta en farmacias, impulsada por la fábrica de plantillas, que son un ejemplo claro del interés por la elaboración de auxiliares del calzado encaminados a favorecer la salud del pie. Una de las bodegas afirma que recurre a la mediación de importadores para facilitar la entrada de sus vinos en mercados extranjeros. La figura 10 recoge los principales canales de venta de las empresas encuestadas y muestra los interesantes contrastes existentes entre las de calzado y las bodegas.

Los actores económicos de los vinos de la DO Calatayud utilizan diferentes canales de venta en sus bodegas. Seis de las encuestadas así lo confirman. Otras tres bodegas utilizan a los distribuidores como único canal; otra empresa, una pequeña bodega, que elabora únicamente vinos de gama alta, vende el $100 \%$ de su producción de forma directa en la propia bodega. Existen otras cuatro bodegas que venden también directamente una parte importante de su producción. En el caso del calzado, las respuestas confirman que las zapaterías son el principal canal de venta; cuatro de las encuestadas venden de este 
modo entre el 80 y el 100\% de su producción. Por otra parte, sólo una empresa vende en grandes superficies y otra ofrece sus productos en comercios especializados tipo boutique. Los precios de los vinos de la DO varían según el lugar donde los adquiere el consumidor. La figura 11 describe los precios máximos declarados por las bodegas según el segmento de calidad y el canal de venta.

Figura 10: Proporción de empresas según los canales de venta que utilizan.

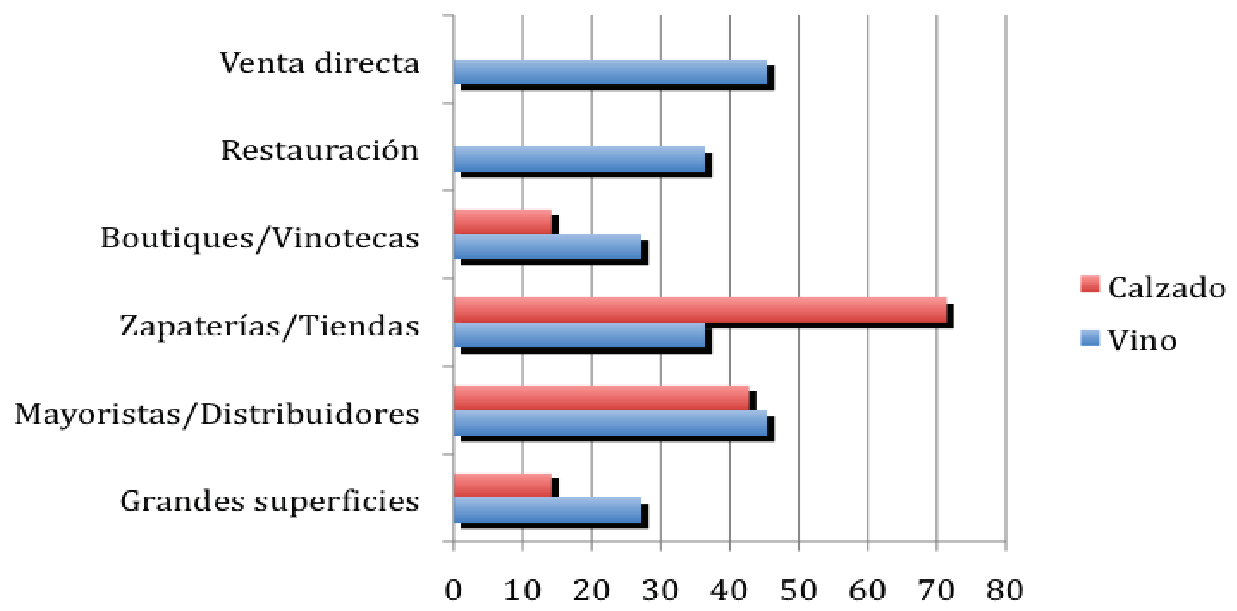

Fuente: Encuesta a los empresarios del vino y del calzado

Figura 11: Precio máximo de la botella según segmento de calidad y canal de venta.

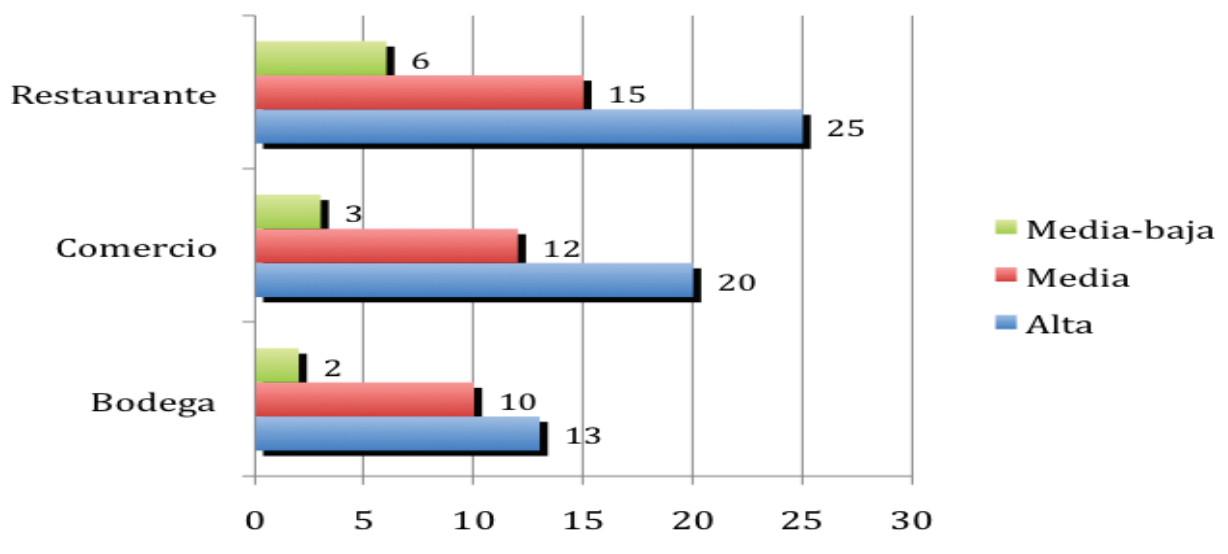

Fuente Encuesta a los empresarios del vino y del calzado 


\subsubsection{La apuesta por la internacionalización de los mercados}

Los mejores mercados son aquéllos en los que se valora y remunera adecuadamente a los productos por su calidad y los que se sitúan en regiones en las que hay un importante consumo y no hay producción propia. Los calzados producidos en el valle del Aranda tienen una presencia consolidada en los países europeos. Destaca Francia, como destino tradicional del mercado español, junto con Alemania. No obstante la encuesta recoge que las exportaciones a otros países europeos como Italia, Grecia y Portugal, se incrementan; este último ha sido el primer mercado en 2009 para la producción de calzado de las empresas del valle del Aranda. El caso de Italia es revelador de la calidad del producto exportado por las empresas zaragozanas, dado que este país es una reconocida potencia a escala mundial en la fabricación de calzado de calidad. También cabe destacar la reciente y prometedora penetración en Japón.

Para los vinos de la DO Calatayud América del Norte, especialmente los Estados Unidos, son, como ya se ha expuesto, el principal destino de sus exportaciones, con un $54 \%$ del total de las mismas. Cinco de las diez empresas encuestadas están presentes en dicho mercado y dos más en el canadiense. Cabe citar también que las exportaciones se dirigen a algunos de los nuevos países productores de vino, como Nueva Zelanda, o a aquéllos en los que crece el consumo, como Japón o la India. Paralelamente se mantiene la presencia en países europeos como Bélgica, Suiza o Finlandia, que destacan por el crecimiento de las importaciones de vinos españoles y por el precio de venta (Observatorio, 2010).

La encuesta revela que la exportación, en mayor o menor proporción, es una salida necesaria para la producción. Nueve de las once bodegas están presentes en numerosos mercados internacionales (figura 12). Lo mismo sucede en el sector del calzado, ya que seis de las siete empresas encuestadas orientan a ella parte de su producción, siguiendo una práctica acorde con las convenciones comerciales.

Sin embargo, cabe destacar la importancia del mercado interior como principal destino de la producción de algunas empresas de la DO. Ello la diferencia de otras DO aragonesas, como la de Cariñena, en la que la producción para la exportación alcanza una proporción notablemente superior (Loscertales, 2009). No hay que olvidar que el mercado interior del vino en nuestro país, no tiene una situación fácil debido al exceso de producción y al descenso del consumo por los cambios de hábitos de los consumidores y por la crisis económica; a ello hay que sumar la creciente presencia de vinos importados de otros ámbitos. 
Figura 12: Proporción de ventas en el mercado nacional e internacional

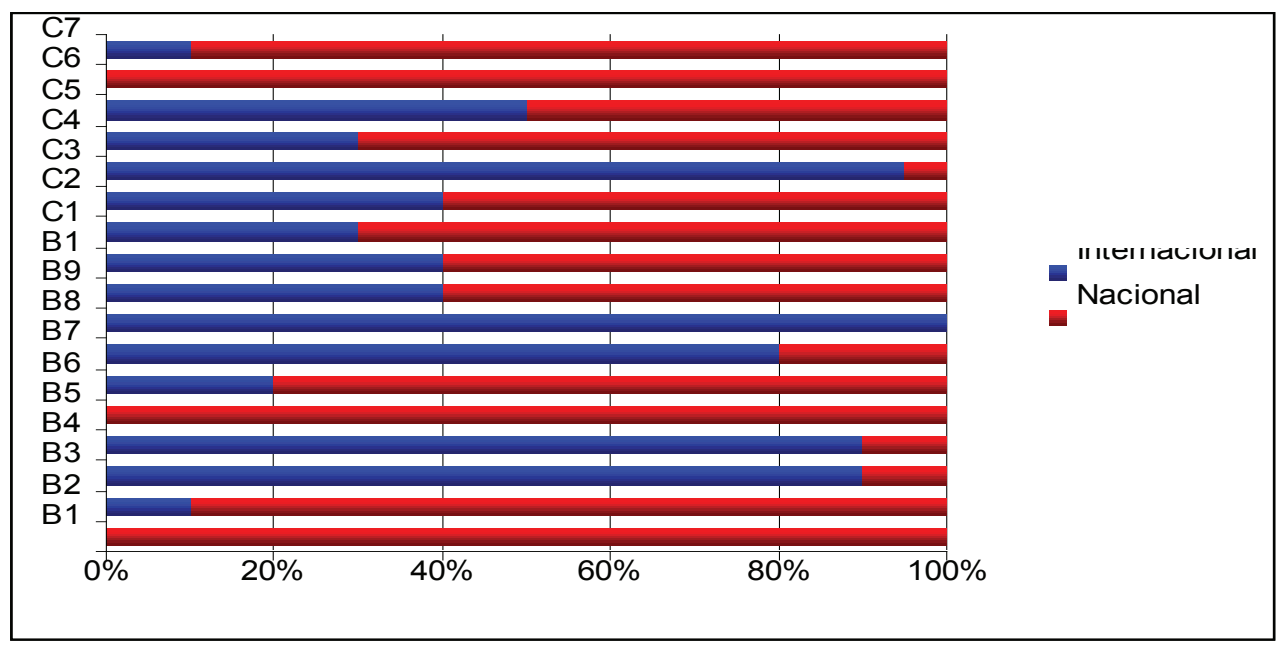

Fuente: Encuesta a las bodegas (B) y a las empresas del calzado (C)

\subsection{PAUTAS PARA EL DESARROLLO EMPRESARIAL Y TERRITORIAL}

En el tercer bloque de la encuesta los empresarios expresan su percepción sobre la situación económica de las dos zonas y manifiestan su preocupación por la situación. Todas las empresas del calzado encuestadas y ocho de las nueve bodegas opinan que la situación de ambos sectores en sus territorios es mala o preocupante. Las bodegas lo atribuyen a los problemas generales del sector vitivinícola ya mencionados, como la alta competencia, los elevados costes, los impagos, los precios bajos o la deficiente relación calidad-precio. La encuesta deja entrever el conflicto existente entre las cooperativas y las demás empresas, que critican a aquéllas por vender a "precios bajos" en un mercado ya muy saturado. A los empresarios del calzado les preocupa también la falta de consumo. Paralelamente esbozan diversas propuestas para su mejora. Sus respuestas dejan claro el aprecio de sus actores por lo local y territorial (convenciones domésticas). La mayoría de las empresas reconocen que la situación en sus territorios es igual de compleja que en otros lugares de España; cuatro empresas encuestadas (dos del sector del calzado y dos bodegas) afirman que la situación es peor. Otros problemas locales citados en el ámbito del vino son la falta de viticultores por el envejecimiento de la población, el arranque de viñas centenarias de calidad incentivado por las ayudas de la Unión Europea o el bajo precio que pagan las cooperativas por las uvas, causando el desánimo de los agricultores.

Estas respuestas justificarían la aplicación a escala local de diferentes medidas impulsadas por las Administraciones Públicas, agentes esenciales del desarrollo económico y territorial. En esta línea, nueve de las diez bodegas y seis de las siete empresas de calzado opinan que el apoyo de las administraciones debe mejorar y realizan diversas propuestas para ello. Destacan, entre ellas, facilitar la actividad empresarial, defendiendo a las empresas de los riesgos de los impagos, racionalizando los procedimientos que les 
resulten gravosos o apoyándolas en su realización o tramitación. A estas medidas podrían añadirse otras no citadas expresamente en la encuesta, pero igualmente necesarias, como la mejora de las condiciones de financiación de las empresas locales (Escalona et al., 2009). Cuatro bodegas y una empresa de calzado reclaman ayudas específicas en el ámbito de la promoción y búsqueda de nuevos mercados. Es muy interesante la propuesta de una bodega que demanda recursos para realizar acciones de promoción pequeñas y con gran impacto, porque percibe que las grandes acciones institucionales no llegan.

La percepción de la compleja situación actual no impide que los encuestados en seis de las ocho bodegas y en cinco de las seis empresas de calzado opinen que la elaboración de vino y la fabricación de calzado y de sus componentes pueden seguir siendo sectores clave para la economía de sus territorios. Una bodega supedita esta posibilidad a que se valore más el producto. En esta línea resultan muy interesantes las recomendaciones de las empresas sobre qué estrategias de mejora debería adoptar su sector. En la figura 13 se recogen las opciones propuestas en la encuesta, según la proporción de empresas que las seleccionan.

La opción de contar con una marca propia fue propuesta únicamente a las empresas del calzado, siendo seleccionada por el $66 \%$ de las empresas que respondieron a esta pregunta. Es interesante apreciar que una buena parte de las empresas de ambos sectores considera necesario mejorar la difusión del producto y ajustar la relación calidad precio. También coinciden en recomendar mejoras en la calidad de los productos. Los principales contrastes se dan en la estrategia de producción, ya que las empresas de calzado son partidarias de la especialización mientras que las del vino prefieren la diversificación. Las empresas de calzado también seleccionan entre sus respuestas la mejor presentación de los productos, aspecto bastante menos citado por las bodegas, sin duda por la mayor práctica en este campo.

Figura 13: Ámbitos para la mejora de las estrategias empresariales (\% de empresas que los seleccionan en sus respuestas).

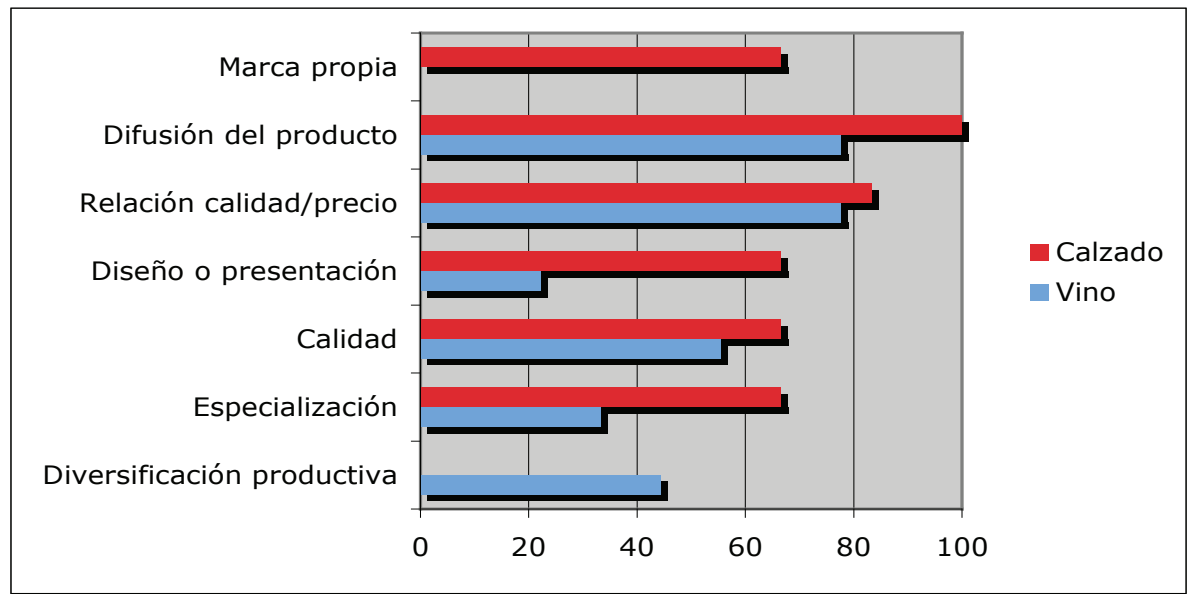

Fuente: Encuesta a los empresarios del vino y del calzado 
En la encuesta se solicitaba a las empresas que puntuasen las opciones propuestas según su importancia. La figura 14 sintetiza las respuestas dejando patente la existencia de más diferencias sectoriales que en el caso anterior. En las bodegas las estrategias prioritarias se relacionan más con el producto que con los procesos. Son las de difusión y mejora de su calidad, ajustar mejor la relación calidad-precio y mejorar la presentación de los vinos (botella y etiquetado). Ya hemos expuesto que en el mundo del vino las innovaciones en los procesos se difunden con rapidez y que es mayor el valor creado por las innovaciones centradas en los productos. Las empresas de calzado ponen su énfasis en la mejora del diseño, pero valoran también la especialización productiva. Las estrategias enfocadas a mejorar la difusión del producto y su calidad obtienen puntuaciones ligeramente menores aunque superiores a las de contar con marca propia y afinar el ajuste de la relación calidad-precio.

Figura 14: Estrategias empresariales recomendadas (porcentaje de puntuación recibida respecto de la máxima posible).

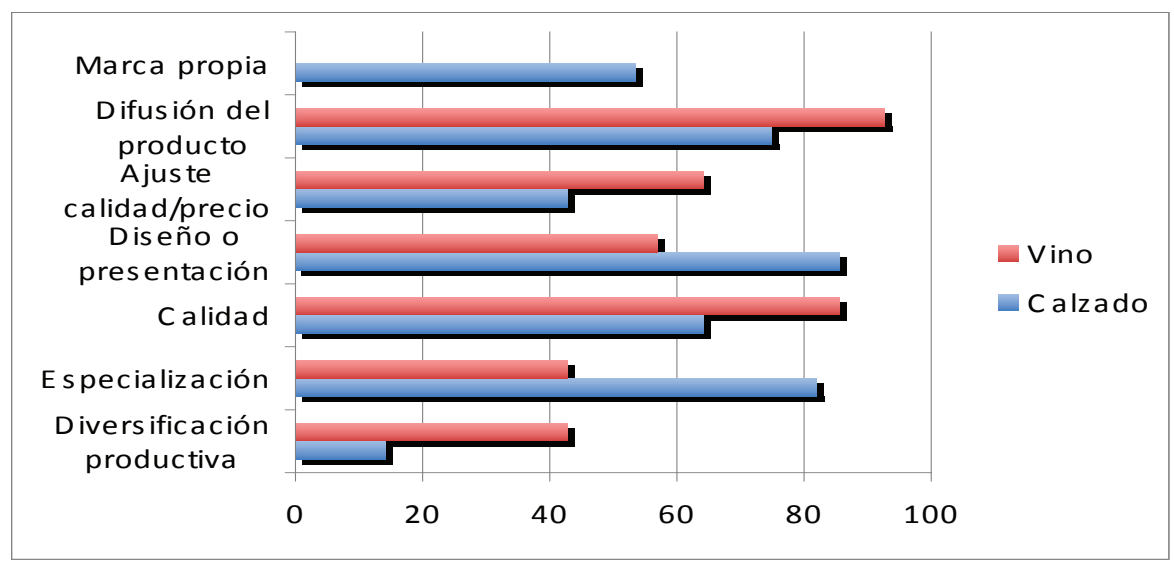

Fuente: encuesta a las empresas

La parte final de la encuesta se refiere a las relaciones entre la empresa y su territorio. Éstas cada vez más se mueven por la voluntad de manifestar su aprecio por lo local, sabedoras de que ello es altamente valorado por determinados segmentos de consumidores (tabla 1 y ejemplos de prácticas empresariales derivados de las convenciones domésticas en la tabla 2). La existencia de una denominación de origen facilita la asociación explícita del producto y sus características y calidad con el territorio concreto en el que se obtiene y con las prácticas culturales que le son propias. Sin embargo llama la atención que tres de las diez bodegas encuestadas de la DO Calatayud no vean ventajas, porque entienden que no todas las bodegas reciben un trato semejante en el seno de la DO o que incluso en ocasiones ésta supone una limitación de su potencial productivo. Una de ellas entiende que el "paraguas" de la DO puede impedir que el cliente llegue a conocer realmente las características del terruño en el que se obtiene el vino. 
Estos resultados son interesantes porque recogen el debate actual sobre la figura jurídica de la "Denominación de Origen" y su función. Sin embargo, este debate no cuestiona que la imagen de los vinos se promocione asociada al territorio, algo que parece bien a todas las bodegas encuestadas. En la justificación de esta respuesta se aprecia que las bodegas valoran la contribución del sector vitivinícola a la promoción y desarrollo de su territorio y, a la inversa, la influencia positiva del territorio y de su historia de cara a la promoción de los vinos, porque les confiere un carácter "exclusivo" y un valor emocional que "ayuda a fidelizar clientes". Esto prueba uno de los supuestos del nuevo paradigma rural: la interdependencia positiva que se establece entre el territorio y los productos locales. El territorio se convierte en un importante escenario activo y los productos serán los mejores embajadores del mismo (Maby, 2000; Escalona et al., 2009; Loscertales, 2009).

La asociación entre el producto y el territorio aparece menos asumida por las empresas de calzado; dos de las encuestadas opinan que no es algo positivo y tres no se pronuncian. Ello puede deberse a la percepción de que la fabricación de calzado, como otras de carácter manufacturero, es una actividad desterritorializada, porque en la valoración de su producto resulta indiferente el lugar de producción. Sin embargo, cada vez más existen productos de un alto valor añadido, como los de la alta costura, la joyería, la artesanía, el diseño, entre otros, cuyo lugar de fabricación, o al menos de diseño, es significativo y queda reflejado en el precio final (Maby, 2002). Ello puede justificar que dos empresas encuestadas consideren positivo favorecer una imagen del producto asociada a su territorio, habida cuenta de la larga tradición zapatera existente en este espacio de la provincia de Zaragoza. No coinciden, sin embargo, en cómo formalizar esta asociación, ya que sólo una cree que podría ser ventajosa una figura jurídica del tipo de las ya implantadas en las áreas vitivinícolas, como la Denominación de Origen, la Indicación Geográfica Protegida, la $C$ de calidad u otras.

\section{POSIBLES ESTRATEGIAS DE FUTURO}

Los cambios que han tenido lugar en los mercados nacionales e internacionales están en la base de los diferentes impactos y retos económicos que tienen planteados las empresas del vino y del calzado en el territorio estudiado. La elaboración de los resultados de la encuesta ha puesto de manifiesto que, a pesar de la situación compleja y difícil que atraviesan, muchas de sus empresas siguen, sin embargo, apostando por la calidad, la innovación, la imagen, la internacionalización o la cooperación. En esta parte final del artículo, queremos llevar a cabo una serie de reflexiones y propuestas concretas para favorecer y reforzar no solo la competitividad actual y futura de las empresas, sino también del territorio al considerar que sólo así será posible lograr un desarrollo endógeno sostenible.

El concepto de desarrollo rural es complejo y cambiante, como también lo son las políticas enfocadas a su consecución. Éstas debe integrar de forma armónica diferentes aspectos entre los que se puede citar un crecimiento económico y del empleo, un alto grado de bienestar y equidad social y una eficaz protección del patrimonio y de la calidad del medio ambiente (Albertos et al, 2004). Su consecución es un reto y 
requiere que se diseñen estrategias adecuadas. En esta línea, el nuevo paradigma rural incorpora interesantes cambios respecto de enfoques anteriores (tabla 3). El modelo es muy interesante porque diversifica y amplia las diferentes actuaciones propias de las políticas rurales. La competitividad, objetivo general, aparece fuertemente apoyada en un aprovechamiento pleno de todos los recursos locales disponibles. En esta línea, el modelo propuesto asume que las llamadas especificidades locales, ya sean de carácter patrimonial, medioambiental o productivo, pueden generar nuevas ventajas competitivas para los territorios. Destaca igualmente el paso desde un enfoque sectorial, centrado en subsidiar actividades en declive, a otro plurisectorial consistente en invertir en las actividades que se consideren estratégicas para los territorios.

La investigación realizada deja patente que la producción de vino y de calzado en el territorio estudiado reúne todos los requisitos para ser considerada estratégica en el marco de los nuevos modelos de desarrollo rural, ya que hace más competitivo al territorio. Enumeramos a continuación algunas líneas de acción que recogen los diversos análisis y propuestas de los actores locales:

Tabla 3. El nuevo paradigma rural.

\begin{tabular}{|l|l|l|}
\hline & Viejo enfoque & Nuevo enfoque \\
\hline Objetivos & $\begin{array}{l}\text { Igualdad, mejora de las rentas } \\
\text { agrarias, competitividad } \\
\text { agraria }\end{array}$ & $\begin{array}{l}\text { Competitividad de las áreas rurales, } \\
\text { valoración de los recursos rurales, } \\
\text { explotación de recursos inutilizados }\end{array}$ \\
\hline $\begin{array}{l}\text { Sectores de } \\
\text { interés }\end{array}$ & Agrario & $\begin{array}{l}\text { Diversos sectores de la economía rural } \\
\text { (turismo, industria, entre otros) }\end{array}$ \\
\hline $\begin{array}{l}\text { Principales } \\
\text { herramientas }\end{array}$ & Subsidios & Inversiones \\
\hline Actores clave & $\begin{array}{l}\text { Administración Central, } \\
\text { población ocupada en el sector } \\
\text { primario }\end{array}$ & $\begin{array}{l}\text { Todos las Administraciones } \\
\text { competentes (desde las supranacionales } \\
\text { a las locales) y los diferentes actores } \\
\text { locales tanto públicos como privados }\end{array}$ \\
\hline
\end{tabular}

Fuente. OECD, 2006; traducción propia. 
1. Mejora sustancial de diferentes ámbitos en los que las empresas desarrollan su actividad y que les afectan indirectamente. Para ello no debe olvidarse la necesidad de adaptar las infraestructuras de transporte y telecomunicaciones de los territorios a las necesidades de unas actividades cada vez más internacionalizadas.

2. Aplicación a escala local de diferentes medidas enfocadas especialmente a facilitar las condiciones de financiación de las empresas locales, defenderlas de los riesgos de los impagos, favorecer el relevo generacional, mejorar la cualificación de los empresarios en todos los aspectos, tanto técnicos como de dirección, reforzar la capacidad de innovación individual, el acceso a los diferentes servicios.

3. Fomento de iniciativas para ayudar al empresariado local en la búsqueda de nuevos mercados, la difusión de sus productos, la mejora de su imagen, el incremento de su valoración, acorde con su calidad y singularidad, la puesta en marcha de diferentes proyectos de innovación y desarrollo.

4. Refuerzo de la competitividad de la producción mediante un mejor conocimiento del producto en los mercados a diferentes escalas.

5. Promoción de todos aquellos aspectos relacionados con la imagen del territorio que pongan de relieve que la singularidad de la producción tiene su origen en la vinculación con el territorio. En este sentido es esencial adoptar medidas explícitas para asociar las producciones de calidad al territorio.

\section{CONCLUSIÓN}

Los sectores productivos del vino y del calzado tienen una importancia fundamental en el área estudiada. Las diversas características del territorio y la tradición preindustrial están en el origen de las mismas. En la DO Calatayud los factores medioambientales favorecen en especial el cultivo de la garnacha tinta. En el Valle del Aranda diferentes empresas familiares orientan su producción al calzado o cuentan con industrias auxiliares del mismo, lo que favorece la subcontratación e interrelación de las mismas. Situándose en el primer lugar de Aragón por su producción, el valle del Aranda no sólo abastece al mercado nacional, sino que ya desde los años sesenta del pasado siglo exportaba una parte de la misma a los Estados Unidos.

Para ello, los diferentes actores económicos y sociales han puesto y deben seguir esforzándose por poner en marcha y potenciar determinadas estrategias que les permitan seguir siendo competitivos en un momento en el que la mundialización se ha convertido en la gran protagonista del espacio económico a todas las escalas. El mercado global ha dado lugar a un intenso proceso de reestructuración en el que destaca el fuerte incremento de la competencia. A nadie se le escapa que los actores económicos deben y deberán afrontar en un futuro diferentes problemas y retos propios de los cambios en la producción y en los mercados; pero también se han tenido que adaptar a las preferencias de los consumidores en ambos sectores. La elaboración de los resultados de la encuesta nos ha permitido caracterizar a las diferentes empresas, su trayectoria y objetivos recientes, conocer sus diferentes estrategias en aspectos como la calidad, innovación, imagen e internacionalización, e 
identificar las principales fortalezas, oportunidades, amenazas y debilidades de ambos sectores. La teoría de las convenciones ha proporcionado un marco teórico útil y la forma en la que se presenta en el texto, en relación con las expectativas que sustentan las diferentes prácticas empresariales y aportando ejemplos de las mismas, constituye una primera aportación para facilitar aplicaciones posteriores más ambiciosas.

En el caso del vino, la competencia producida por la entrada en el mercado global de nuevos países exportadores, el descenso del consumo del vino por diferentes causas, la proliferación de denominaciones de origen en el ámbito nacional, son algunas de las principales debilidades y amenazas identificadas, especialmente patentes en el mercado interior. Entre las fortalezas y oportunidades cabe citar la apuesta de los consumidores por un vino de calidad garantizada, el reconocimiento de la misma en diferentes certámenes y publicaciones de gran prestigio, tanto nacionales como internacionales, y la creciente apertura al mercado exterior con la entrada de nuevos ámbitos importadores. La preocupación por la comercialización es una constante y ante la difícil situación del mercado interior, los diferentes vinos de la DO se esfuerzan por penetrar con fuerza en el mercado internacional. El volumen de las exportaciones es actualmente elevado y una apuesta de futuro.

En el caso de la industria del calzado, cabe destacar el gran esfuerzo realizado por los actores locales para adoptar nuevas estrategias como la deslocalización industrial o la puesta en marcha de actividades relacionadas con la comercialización de la producción, haya sido o no producida en el área, lo que favorece la creación de nuevos puestos de trabajo. Del análisis realizado se deduce también que el calzado de gamas media y alta tiene un acceso más fácil al mercado. El saber hacer, la tradición y la muy positiva relación calidad-precio, hacen que el sector, a pesar de sus dificultades, sobreviva mejor que en otras áreas de España. Así lo han venido confirmando diferentes actores económicos y de la Administración a diferentes niveles. En esta área existen empresas punteras que, como ya es una realidad en el caso del vino, podrían proyectar en un futuro una imagen asociada a la de la Comarca.

Los actores económicos de este sector deben afrontar diferentes medidas, como seguir apostando por el diseño, dar a conocer y mejorar la imagen de los productos, mejorar el marketing, crear una marca propia, fortalecer el cluster del calzado al máximo, fomentar la cooperación empresarial como una herramienta para poder sobrevivir, utilizar todos los canales de comercialización posibles, incluida la comercialización directa y orientarlos a los nichos de mercado adecuados, mejorar la gestión y la administración, ya que existen fuertes deficiencias y carencias evidentes, apostar por la investigación y por la formación de recursos humanos en aspectos diferentes a los propiamente productivos.

La explotación de la encuesta nos ha permitido conocer otros muchos aspectos de las empresas y de sus trayectorias, poniendo de manifiesto la fuerte heterogeneidad empresarial existente. Del análisis comparado de las de ambos sectores se deduce la existencia de muchos aspectos comunes, pero también de notables diferencias, hecho lógico, si se considera la diferente situación de la que parten y los objetivos que se proponen los empresarios. 
El análisis realizado muestra la importancia que pueden tener las producciones locales tradicionales o contar con una DO para el desarrollo endógeno de un territorio rural, pero para que esto sea una realidad, junto a la tradición y el saber hacer tradicional, hace falta inversión e innovación. Las empresas de ambos sectores sólo podrán seguir jugando un importante papel en el desarrollo rural de unas áreas calificadas como zonas rurales a revitalizar si adaptan sus procesos productivos y adecuan sus productos para que puedan introducirse en los nichos de mercado en los que puedan ser más competitivos.

\section{BIBLIOGRAFÍA}

ALBISU AGUADO, L.M. (2005): La industria agroalimentaria y su necesidad de profesionales especializados. Agricultura. Revista agropecuaria, 873, 288-290.

BARCO ROYO, E. (2007): Denominaciones de origen. Distribución y consumo, 96, $27-41$.

BARCO ROYO, E., Pinillos García, M.O. y Navarro Pérez, M.C. (2006): Estrategias de diversificación versus estrategias de tamaño. Cuaderno de Campo, 34, 12-16.

CAI (Caja de Ahorros de la Inmaculada): Empleo y población en los municipios $y$ comarcas de Aragón http://www.cai.es/sestudios/paginas/paginafinal. asp?idNodo=712 [consulta: 9-6-2010]

ESCALONA ORCAO , A.I., Loscertales Palomar, B. y Climent López, E. (2009): Nuevos retos para el desarrollo territorial: los espacios del vino y del calzado en la provincia de Zaragoza. Zaragoza, Diputación Provincial de Zaragoza http://www.dpz.es/diputacion/areas/presidencia/4espacio/documentos/premios/ nuevos_retos_territorial09.pdf [consulta: 20-7-2010]

ESCALONA ORCAO, A.I., Loscertales Palomar, B. Y Climent López, E. (2010): Nuevos retos empresariales en las áreas rurales. Convenciones y estrategias de las industrias del vino y del calzado en la provincia de Zaragoza. En XII Congreso Ibérico de Geografia (en prensa).

FICE (Federación de Industrias del Calzado Español) (2008): El sector del calzado, informe anual $2008 \mathrm{http}: / /$ www.fice.es/index.php?option=com_content\&task=vie $\mathrm{w} \& \mathrm{id}=151 \&$ Itemid=126 [consulta: $11-6-2010$ ]

LINDKVIST, K.B. y Sánchez, J.L. (2008): Conventions and innovation: a comparison of two localized natural resource-based industries. Regional Studies, 42, 343-354.

LOSCERTALES PALOMAR, B. (2009): La Denominación de Origen Cariñena: una apuesta por la singularidad y la calidad en un mundo globalizado. Zaragoza, Ediciones 94. 
MINISTERIO DE MEDIO AMBIENTE Y MEDIO RURAL Y MARINO (2010): Ley para el desarrollo sostenible del medio rural http://www.mapa.es/es/desarrollo/ pags/ley/ley.htm [consulta: 14-7-2010]

MONTEALEGRE GRACIA, A.L. (2009): Caracterización y perspectivas de las empresas fabricantes de calzado de Aragón en el contexto de la mundialización. Proyecto fin de carrera, dirigido por A.I. Escalona Orcao. Zaragoza, Universidad de Zaragoza.

MURDOCH, J., MARSDEN, T. Y BANKS, J. (2000): Quality, nature and embeddedness: some theoretical considerations in the context of the food sector. Economic Geography, 76, 107-125.

MURDOCH, J. Y MIELE, M. (1999): Back to nature: changing worlds of production in the food sector. Sociologia ruralis, 39, 465-483.

OBSERVATORIO ESPAÑOL DEL MERCADO DEL VINO (2010): 2009, un año dificil para las exportaciones de vino. http://www.oemv.es/noticia_amp. php?id=00000017012 [consulta 15-7-2010]

PONTE, S. (2009): Governing through quality: conventions and supply relations in the value chain for South African wine. Sociologia ruralis, 49, 236-257.

SALAIS, R. Y STORPER, M. (1992): The four worlds of contemporary industry. Cambridge Journal of Economics, 16, 169-193.

SÁNCHEZ-HERNÁNDEZ, J.L., Aparicio-Amador, J. y Alonso-Santos, J.L. (2010): The shift between worlds of production as an innovative process in the wine industry in Castile and Leon (Spain). Geoforum, 41, 469-478. 